\title{
Universiteit
}

Leiden

The Netherlands

\section{Validity, reliability, and feasibility of a quality of life questionnaire for people with dementia}

Dichter, M.; Bartholomeyczik, S.; Nordheim, J.; Achterberg, W.; Halek, M.

\section{Citation}

Dichter, M., Bartholomeyczik, S., Nordheim, J., Achterberg, W., \& Halek, M. (2011). Validity, reliability, and feasibility of a quality of life questionnaire for people with dementia, 44(6), 405-410. doi:10.1007/s00391-011-0235-9

Version: $\quad$ Not Applicable (or Unknown)

License: $\quad$ Leiden University Non-exclusive license

Downloaded from: https://hdl.handle.net/1887/117607

Note: To cite this publication please use the final published version (if applicable). 
Z Gerontol Geriat $2011 \cdot 44: 405-410$ DOI 10.1007/s00391-011-0235-9

Online publiziert: 1. Oktober 2011

(c) Springer-Verlag 2011

M. Dichter ${ }^{1,2}$ - S. Bartholomeyczik ${ }^{1,2} \cdot$ J. Nordheim ${ }^{3} \cdot$ W. Achterberg $^{4} \cdot$ M. Halek ${ }^{1}$

${ }^{1}$ Deutsches Zentrum für Neurodegenerative Erkrankungen (DZNE), Witten

${ }^{2}$ Department für Pflegewissenschaft, Universität Witten/Herdecke

${ }^{3}$ Institut für Medizinische Soziologie, Charité-Universitätsmedizin Berlin

${ }^{4}$ Department of Public Health and Primary Care, Leiden University Medical Center

\section{Validity, reliability, and feasibility of a quality of life questionnaire for people with dementia}

evaluations in order to prevent high rates of missing data [9].

Furthermore, the instruments can be differentiated with respect to their feasibility, psychometric properties, the stage of dementia in which the application of the instrument is possible, and the underlying definitions and domains of the quality of life $[8,18]$. Some instruments cover primarily functional and cognitive abilities, which is used to measure the health status rather than the quality of life of people with dementia. As dementia inevitably leads to a reduction of cognitive and physical abilities, psychosocial aspects such as social relations, the care relationship, or the experience of being a resident in a nursing home are more relevant domains for assessing quality of life. Based on a literature search [5] in the relevant databases, the QUALIDEM [7] was identified as the instrument with the best psychometric properties and with a focus on the psychosocial domains of quality of life. Therefore, the original Dutch instrument was translated into German and first used in two lighthouse projects for dementia founded by the German Ministry of Health (Leuchturmprojekte InDemA and STI-D). These projects were the framework for this study to evaluate the German version of the QUALIDEM.

\section{Methods}

To evaluate the construct validity and reliability, the baseline data from the InDe$\mathrm{mA}$ (Interdisciplinary Implementation of Quality Instruments for the Care of Resi- dents with Dementia in Nursing Homes) [2] and the STI-D study (Serial Trial Intervention-Germany) [17] were combined. The data were collected at the end of 2008. The feasibility results are based on four interviews which were conducted for this study in 2009. The ethical committee of the Department of Nursing Science of the University of Witten/Herdecke approved the study protocol for this study.

\section{Participants and data collection}

For the investigation of the validity and reliability, both primary study samples were included. This resulted in 486 residents in 34 nursing homes in Germany. The 19 nursing homes included in the STI-D study were located in the Frankfurt/Main area and the 15 nursing facilities of the InDemA project were in the Witten and Dortmund area. Inclusion criteria for the residents were a Mini Mental Status Examination (MMSE) score $\leq 24$ and the residents had to have been living in the nursing home for at least 2 weeks (InDemA) or 4 weeks (STI-D). Exclusion criteria were a documented diagnosis of schizophrenia or other psychotic disorders. Consequently, the sample for this study is not random but heterogeneous in terms of the severity of dementia. This is the major requirement for testing a questionnaire [3].

The study of feasibility is based on interviews with four raters. Due to their involvement in the InDemA project, they had great experience in the application of the QUALIDEM. Thus, they were able to is preferred in the later stages of dementia and also for longitudinal quality of life 
Tab. 1 Sociodemographic characteristics

\begin{tabular}{|lll}
\hline Characteristics & $\begin{array}{l}\text { MMSE } \leq 24 \text { bis } \geq 10 \\
n=203(\%)\end{array}$ & $\begin{array}{l}\text { MMSE }<10 \\
n=283(\%)\end{array}$ \\
$\begin{array}{l}\text { Demographic } \\
\text { Woman }\end{array}$ & $151(74)$ & $223(79)$ \\
\hline $\begin{array}{l}\text { Age, years } \\
\text { Care dependency levels }{ }^{\mathrm{a}}\end{array}$ & $84 \pm 9$ & $86 \pm 8$ \\
\hline None & $6(3)$ & $2(1)$ \\
1 & $87(43)$ & $33(12)$ \\
2 & $97(48)$ & $129(45)$ \\
\hline 3 & $13(6)$ & $119(42)$ \\
\hline $\begin{array}{l}\text { MMSE value } \\
\text { Missing item response }\end{array}$ & $15 \pm 4$ & $3 \pm 3$ \\
abased on the German long-term care insurance beach 37 QUALIDEM items per participant ${ }^{\text {ceach }}$ 18 QUALIDEM \\
items per participantValues are numbers (percentages) or means \pm standard deviation (SD)
\end{tabular}

Screeplot

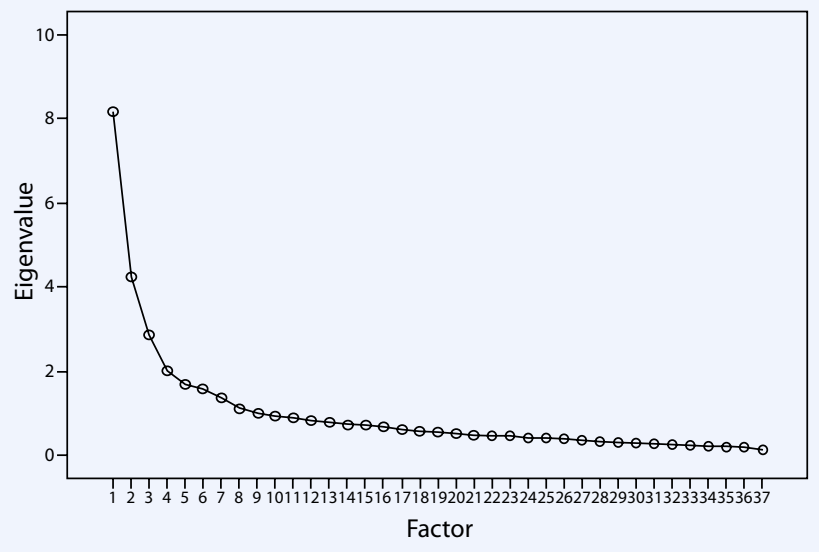

Screeplot

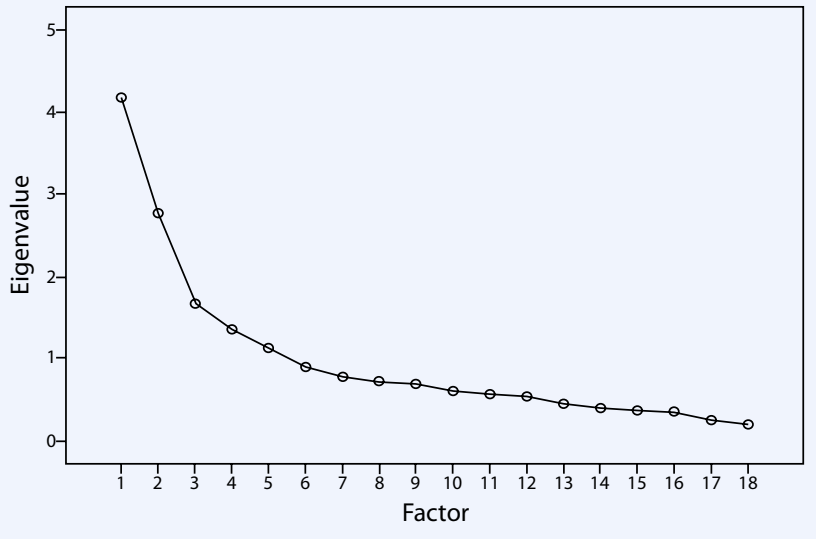

Fig. $1<$ Screeplot for the 37-item version of QUALIDEM $(n=203)$

Fig. $2<$ Screeplot for the 18-item version of QUALIDEM $(n=283)$ judge the practical application of the instrument as experts.

\section{Procedures}

In both primary studies, nurses of different qualification levels (registered nurses and nursing assistants) scored the instrument, based on a retrospective observation period of 2 weeks. One condition, however, was that the nurses had a close relationship to the residents and, thus, knew the residents well. To ensure standardized data collection, the QUALIDEM application was always initiated by external raters who were registered nurses and students of nursing science. They had received prior full-day training on data collection. In addition, the standardization was supported by a comprehensive manual for data collection.

\section{Questionnaire}

The QUALIDEM was developed and validated between 2005 and 2007 in the Netherlands [7]. The instrument consists of two consecutive instrument versions. The quality of life of people with mild to severe dementia can be measured using the 37 -item version, while with the 18 -item version, it is possible to measure the quality of life of people with a very severe dementia. The 37 -item version is divided into 16 indicative and 21 contraindicative items, which are divided into 9 subscales: care relationship, positive affect, negative affect, restless tense behavior, positive self image, social relations, social isolation, feeling at home, and having something to do. The subscales positive self image, feeling at home, and having something to do could not be assessed for people with very severe dementia so that the 18 -item version contains 6 subscales with 7 indicative and 11 contraindicative items. The response options for all items are the following: never, rarely, sometimes, and frequently. The application period in the Dutch studies is specified as $15 \mathrm{~min}$. For the STI-D and InDe$\mathrm{mA}$ studies, the original QUALIDEM was translated by a certified translation agency into German and back-translated into Dutch. The back-translated version was verified by the questionnaire's first author 
and the German version was revised accordingly after his comments.

For the assessment of the severity of dementia, the German version of the MMSE [12] was used. In both primary studies, the MMSE was applied during a rater interview with the nursing home residents. Since the application of the MMSE was associated with stress for many residents, the test was terminated earlier for ethical reasons if it was obvious that a resident would not reach an MMSE value of 10 .

\section{Statistical analysis}

For statistical analysis, the two samples from the STI-D and InDemA studies were combined to form a larger sample. Larger samples tend to produce more accurate factor analysis results. To examine the two versions of the QUALIDEM, the resulting sample was divided in two subsamples, based on the severity of dementia. This was similar to the approach of Ettema et al. [7] and Bouman et al. [3]. Based on the available MMSE data, one subsample of people with mild to moderate dementia (MMSE $\leq 24$ to $\geq 10$ ) and one with severe and very severe dementia $(\mathrm{MMSE}<10)$ were derived. This classification of the disease severity is based on the classification of Reisberg et al. [19]. Furthermore, the definition of severe dementia is based on an MMSE value $<10$, the most widely used classification in clinical trials [20].

All statistical analyses were performed with the Statistical Package for the Social Science (SPSS), version 17. Exploratory factor analysis (principal component analysis) was performed to derive independent subscales for both QUALIDEM versions. Internal consistency was calculated for all resulting subscales, using Cronbach's a coefficient. Missing data were excluded pairwise; thus, the analysis could be performed on the basis of the widest possible sample.

\section{Qualitative analysis}

After a transcription by one investigator (MD), the four expert interviews were examined on the basis of the three closed categories application, structure and content, as well as challenges in the application.

Z Gerontol Geriat 2011 · 44:405-410 DOI 10.1007/s00391-011-0235-9

C) Springer-Verlag 2011

M. Dichter · S. Bartholomeyczik · J. Nordheim · W. Achterberg · M. Halek Validity, reliability, and feasibility of a quality of life questionnaire for people with dementia

\section{Abstract}

The present study investigates the validity, reliability, and applicability of the German version of the QUALIDEM, which is used to measure the quality of life of people with dementia in nursing homes. The sample consists of data from 203 people (average age $84 \pm 9$ years, $74 \%$ female) with mild to moderate dementia and 283 persons (average age $86 \pm 8$ years, $79 \%$ female) with severe to very severe dementia. These are baseline data from two lighthouse projects on dementia (STI-D and InDemA). The investigation of the feasibility is based on four expert interviews. The construct validity of the 37-item version of the QUALIDEM shown by the factors satisfied behavior, unapproachable and unsatisfied behavior, positive self-image, negative affect, social relations, feeling at home, restless tense behavior, and having something to do were identified. Furthermore, for the 18-item version the following four factors were computed: satisfied behavior, unapproachable and unsatisfied behavior, restless tense behavior, and negative affect. Cronbach's a values for the determined factors are between 0.64 and 0.87 (37-item version) and between 0.61 and 0.83 (18-item version), which corresponds with a medium to high reliability (internal consistency). Furthermore, the student assistants assessed the QUALIDEM as applicable and practical.

\section{Keywords}

Quality of life · Aged 80 and over · Nursing homes · Factor analysis, statistical · Dementia

\section{Validität, Reliabilität und Anwendbarkeit eines Lebensqualitätsfragebogens für Menschen mit Demenz}

\section{Zusammenfassung}

Die vorliegende Arbeit untersucht die Validität, Reliabilität und Anwendbarkeit der deutschsprachigen Version des QUALIDEM, mit dessen Hilfe die Lebensqualität von Menschen mit Demenz in der stationären Altenpflege erfasst werden kann. Die Stichprobe besteht aus Daten von 203 Menschen (mittleres Alter $84 \pm 9$ Jahre, $74 \%$ weiblich) mit einer leichten bis mittleren Demenz und 283 Personen (mittleres Alter $86 \pm 8$ Jahre, $79 \%$ weiblich) mit einer schweren bis sehr schweren Demenz. Grundlage sind die Basisdaten aus zwei Leuchtturmprojekten Demenz (STI-D und InDemA). Zur Untersuchung der Anwendbarkeit erfolgten vier Experteninterviews. Die Konstruktvalidität der 37-ItemVersion des QUALIDEM zeigt sich anhand der Faktoren zufriedenes Verhalten, unzugängliches und unzufriedenes Verhalten, positive Selbstwahrnehmung, negativer Affekt, soziale Beziehungen, sich zu Hause fühlen, ruheloses, angespanntes Verhalten und etwas zu tun haben. Daneben konnten für die 18-Item-Version die Faktoren zufriedenes Verhalten, unzugängliches und unzufriedenes Verhalten, ruheloses, angespanntes Verhalten und negativer Affekt berechnet werden. Die Cronbachs a-Werte für die ermittelten Faktoren liegen zwischen 0,64 und 0,87 (37-ItemVersion) sowie zwischen 0,61 und 0,83 (18-Item-Version) und entsprechen somit einer mittleren bis hohen internen Konsistenz als Reliabilität. Ferner wurde das QUALIDEM von den Ratern als anwendbar und praktikabel eingeschätzt.

\section{Schlüsselwörter}

Lebensqualität · Alte Menschen $\geq 80$. Pflegeheime - Faktorenanalyse, statistische . Demenz 
Tab. 2 Rotated factor loadings ( $n=203$ ) for the 37-item version of QUALIDEM

\begin{tabular}{|c|c|c|c|c|c|c|c|c|c|}
\hline \multirow{2}{*}{\multicolumn{2}{|c|}{ Items }} & \multicolumn{8}{|c|}{ Factor } \\
\hline & & \multirow{2}{*}{$\begin{array}{l}1 \\
0.87\end{array}$} & \multirow[t]{2}{*}{2} & \multirow[t]{2}{*}{3} & \multirow[t]{2}{*}{4} & \multirow[t]{2}{*}{5} & \multirow[t]{2}{*}{6} & \multirow[t]{2}{*}{7} & \multirow[t]{2}{*}{8} \\
\hline 10 & Is in a good mood & & & & & & & & \\
\hline 1 & Is cheerful & 0.84 & & & & & & & \\
\hline 21 & Has a smile around the mouth & 0.81 & & & & & & & \\
\hline 5 & Has a contented appearance & 0.80 & & & & & & & \\
\hline 8 & Is capable of enjoying things in daily life & 0.74 & & & & & & & \\
\hline 40 & Mood can be influenced in positive sense & 0.64 & & & & & & & \\
\hline 12 & Responds positively when approached & 0.48 & & & & & & & \\
\hline 26 & Finds things to do without help from others & 0.46 & & & & & & & \\
\hline 14 & Has conflicts with nursing assistants & & 0.79 & & & & & & \\
\hline 7 & Is angry & & 0.74 & & & & & & \\
\hline 17 & Accuses others & & 0.72 & & & & & & \\
\hline 4 & Rejects help from nursing assistants & & 0.69 & & & & & & \\
\hline 20 & Openly rejects contact with others & & 0.62 & & & & & & \\
\hline 31 & Accepts help & & 0.61 & & & & & & \\
\hline 16 & Is rejected by other residents & & 0.61 & & & & & & \\
\hline 33 & Criticizes the daily routine & & 0.55 & & & & & & \\
\hline 24 & Appreciates help he or she receives & & 0.55 & & & & & & \\
\hline 35 & Indicates not being able to do anything & & & 0.76 & & & & & \\
\hline 27 & Indicates he or she would like more help & & & 0.71 & & & & & \\
\hline 37 & Indicates feeling worthless & & & 0.60 & & & & & \\
\hline 32 & Calls out & & & 0.52 & & & & & \\
\hline 11 & Is sad & & & & 0.83 & & & & \\
\hline 23 & Cries & & & & 0.77 & & & & \\
\hline 6 & Makes an anxious impression & & & & 0.64 & & & & \\
\hline 3 & Has contact with other residents & & & & & 0.66 & & & \\
\hline 25 & Cuts himself/herself off from environment & & & & & 0.65 & & & \\
\hline 29 & Is on friendly terms with one or more residents & & & & & 0.61 & & & 0.41 \\
\hline 34 & Feels at ease in the company of others & & & & & 0.61 & & & \\
\hline 36 & Feels at home on the ward & & & & & & 0.75 & & \\
\hline 39 & Wants to get off the ward & & & & & & 0.73 & & \\
\hline 13 & Indicates that he or she is bored & & & & & & 0.51 & & \\
\hline 28 & Indicates feeling locked up & & & & & & 0.43 & & \\
\hline 2 & Makes restless movements & & & & & & & 0.81 & \\
\hline 19 & Is restless & & & & & & & 0.79 & \\
\hline 22 & Has tense body language & & & & 0.38 & & & 0.38 & \\
\hline 18 & Takes care of other residents & & & & & & & & 0.80 \\
\hline & Enjoys helping with chores on the ward & & & & & & & & 0.75 \\
\hline & envalues & 8.2 & 4.2 & 2.9 & 2.0 & 1.7 & 1.6 & 1.4 & 1.1 \\
\hline & f variance & 22.1 & 11.5 & 7.7 & 5.5 & 4.6 & 4.3 & 3.7 & 3.0 \\
\hline & nbach's a & 0.87 & 0.86 & 0.69 & 0.71 & 0.74 & 0.64 & 0.67 & 0.74 \\
\hline
\end{tabular}

\section{Results}

\section{Study population}

The sociodemographic details of the two subsamples for the quantitative analysis are shown in $\bullet$ Tab. 1. to the factor with its highest charge. The Kaiser-Meyer-Olkin (KMO) measure for sampling adequacy was 0.83 (meritorious) for the sample from mild to moderate dementia and 0.76 (middling) for the sample with severe and very severe dementia. This indicates that the sample size was sufficient for factor analysis. All KMO values for individual items (both samples) were $>0.54$, which is well above the acceptable limit of 0.5 [14]. Bartlett's test of sphericity was $\chi^{2}(666)=3397.79, \mathrm{p}<0.001$ (37 items) and $\chi^{2}(153)=1607.28, p<0.001$ (18 items), indicating that correlations between items were sufficiently large for PCA [11]. For both instrument versions initial analyses were run to obtain eigenvalues for each resulting component.

For the 37-item version of the QUALIDEM, eight components had eigenvalues above Kaiser's criterion of 1 and in combination this explained $62.4 \%$ of the variance. The screeplot (• Fig. 1) showed an inflexion that would justify retaining three components.

After examining the 3- and 8-factor solution, the 8-factor solution was chosen because of its content plausibility. The factor loadings after rotation are shown in - Tab. 2. The items that cluster on the same factors suggest the components 1 (satisfied behavior), 2 (unapproachable and unsatisfied behavior), 3 (positive self image), 4 (negative affect), 5 (social relations), 6 (feeling at home), 7 (restless tense behavior), and 8 (having something to do).. Item 22 (has tense body language) showed only 2 factor loadings $<0.4$. Based on the close content, the item was assigned to the factor restless tense behavior.

For the 18 -item version, five components had eigenvalues $>1$. Together these components explain $61.8 \%$ of the variance. The screeplot (• Fig. 2) showed an inflexion that justifies 2 factors. After the examination of the 5- and 2-factor solutions, solutions with 3 and 4 factors were also computed in order to find the solution with the best content plausibility.

The factor loadings after rotation are shown in $\bullet$ Tab. 3. The items which load on the same factor suggest components 1 (satisfied behavior), 2 (unapproachable and unsatisfied behavior), 4 (restless tense behavior), and 3 (negative affect). 


\section{Internal consistency}

The identified subscales for both QUALIDEM versions showed a moderate to high internal consistency. The Cronbach's $a$ values for the eight subscales of the 37 -item version were between 0.87 and 0.64 ( Tab. 2). For the four scales of the 18 -item version, the Cronbach's $\alpha$ values were between 0.83 and 0.61 ( $\mathbf{\bullet}$ Tab. 3).

\section{Feasibility}

There were only a few missing item responses $(\geq 0.2)$ in both subsamples. The QUALIDEM took a maximum of $10 \mathrm{~min}$ to complete and was assessed by the raters as generally applicable and practical.

The structure and content are estimated as logical and sensible. According to the raters the proxy assessment of the quality of life based on the items 5 , 8 , and 25 was sometimes difficult for the nurses. In item 5 (has contented appearance), it was difficult for nurses to judge how satisfaction is expressed. Responding to item 8 (is capable of enjoying things in daily life), it was sometimes challenging to assess what kind of things the residents really enjoy in their daily lives. Item 25 (cuts himself/herself off from environment) was difficult to assess whether social withdrawal was based on physical limitations or on the conscious behavior of the residents. It should be noted that the application of these items was difficult in the end stage of the disease. With few exceptions, the assessment of people with mild to moderate dementia was no prob$\mathrm{lem}$. The response categories never, rarely, sometimes, and frequently were understandable and easy to use.

In applying the QUALIDEM, it was difficult for some nurses to consider only the specified assessment period of the last 2 weeks. This sometimes led to an extended assessment period, especially in the assessment of the more difficult items mentioned above. In the application of item 2 (makes restless movements) and 19 (is restless), another sporadically occurring problem was reported, especially if nurses with migration background did not have sufficient language skills to understand the meaning of restless. Finally, items 16 (is rejected by other residents), 20

\begin{tabular}{|c|c|c|c|c|c|}
\hline \multirow[t]{2}{*}{ Items } & & \multicolumn{4}{|c|}{ Factor } \\
\hline & & 1 & 2 & 3 & 4 \\
\hline 21 & Has a smile around the mouth & 0.81 & & & \\
\hline 5 & Has a contented appearance & 0.80 & & & \\
\hline 8 & Is capable of enjoying things in daily life & 0.77 & & & \\
\hline 12 & Responds positively when approached & 0.75 & & & \\
\hline 40 & Mood can be influenced in positive sense & 0.73 & & & \\
\hline 3 & Has contact with other residents & 0.59 & & & \\
\hline 31 & Accepts help & 0.48 & 0.45 & & \\
\hline 14 & Has conflicts with nursing assistants & & 0.81 & & \\
\hline 7 & Is angry & & 0.74 & & \\
\hline 20 & Openly rejects contact with others & & 0.71 & & \\
\hline 16 & Is rejected by other residents & & 0.49 & 0.42 & \\
\hline 19 & Is restless & & & 0.85 & \\
\hline 2 & Makes restless movements & & & 0.84 & \\
\hline 32 & Calls out & & & 0.42 & \\
\hline 6 & Makes a anxious impression & & & & 0.79 \\
\hline 23 & Cries & & & & 0.68 \\
\hline 22 & Has tense body language & & & & 0.64 \\
\hline 25 & Cuts himself/herself off from environment & & & & 0.47 \\
\hline Eigenvalues & & 4.2 & 2.8 & 1.7 & 1.4 \\
\hline$\%$ of variance & & 23.2 & 15.4 & 9.3 & 7.6 \\
\hline Cronbach's a & & 0.83 & 0.72 & 0.62 & 0.61 \\
\hline
\end{tabular}

(openly rejects contact with others), and 32 (call outs) from the subscale social isolation were difficult to answer if the residents were isolated due to certain reasons (e.g., because of multiresistant infections). Here the nurses usually assessed the items on observations over an extended assessment period.

\section{Discussion}

The factor analysis performed provides first evidence for the construct validity of the QUALIDEM in Germany. For the 37 -item version, the following factors were identified: satisfied behavior, unapproachable and unsatisfied behavior, positive self-image, negative affect, social relations, feeling at home, tense behavior, and having something to do. Moreover, for the 18 -item version the four factors satisfied behavior, unapproachable and unsatisfied behavior, restless tense behavior, and negative affect were computed. The largest differences between previous investigations in the Netherlands $[3,7]$ and this study were found for the subscales unapproachable and unsatisfied behavior, which had originally been named as care relationship. In addition to all items of the original subscale care relationship, item 16 (is rejected by other residents) and item 20 (openly rejects contact with others) also load on the factor unapproachable and unsatisfied behavior. This unapproachable and unsatisfied behavior leads to a change in the content interpretation of the factor. Because of the objective that the QUALIDEM recognizes care relationship as an important dimension of the quality of life of people with dementia [6], it should be considered whether a selection of items is useful for a scale to obtain care relationship. An analysis not published here shows that the selection of the items results in the original subscale care relationship with only slight changes in the individual factor loadings. With an item selection, the obtained results should be controlled in further studies. A possible item selection should be taken, based on considerations of content validity. Moreover, the original subscale social isolation could not be determined for both versions of the instrument and the factor social relations could not be identified for the 18 -item version of the QUALIDEM. These results are similar to the ones of Bouman, et al. [3]. In 
this Mokken Scale, analysis of the 37-item version the subscale social isolation was not scalable, while for the 18 -item version, the subscale social relations was not scalable and the subscale social isolation was only weakly scalable.

The internal consistency is moderate (o.64) to high (0.87) for the subscales of the 37 -item version and $0.61-0.83$ for the factors of the 18 -item version. These results are similar to the Dutch version of the instrument $[3,7]$. The investigation of internal consistency is only the first step in the evaluation of reliability. Therefore, in future studies, the interrater reliability and test-retest reliability in particular must be examined.

The 37-item version of the QUALIDEM can be considered as feasible. This is suggested by the application duration of a maximum of $10 \mathrm{~min}$, the low number of missing values, and the structure and content of the instrument, which was assessed as logical and sensible. Only a few items caused problems in the application. For the proxy-rating nurses, it was sometimes difficult to recognize observable behavior in order to answer items 5 (has contented appearance) and 8 (is capable of enjoying things in daily life), which describe an internal emotional state. For the future, the development of an application manual with examples for possible observable behavior is desirable. Furthermore, item 2 (makes restless movements) and 19 (is restless) were difficult to answer if the nurse's knowledge of the German language was too low. In the light of the increasing proportion of nurses with an immigrant background [1], these difficulties are particularly important. In addition to an application manual with descriptions of certain terms, the definition of inclusion and exclusion criteria for the nurses conducting proxy ratings might help to support the application of the instrument. In addition, it should be examined whether the wording of the items can be clarified. Finally, the items from the subscale social isolation 16 (is rejected by other residents), 20 (openly rejects contact with others), and 32 (call outs) as well as item 25 (cuts himself/herself of from environment) were difficult to answer if the residents were isolated because of certain reasons not related to the conscious behav- ior of the residents. In the further development of the QUALIDEM, the possibility to comment on the answer of items will be one opportunity for identifying such cases and excluding them from certain analysis. In the previous Dutch studies of the QUALIDEM, no problems in the application of individual items were reported [3, 7]; however, no questioning of the nurses conducting proxy ratings was performed.

\section{Limitations of this study}

The results for feasibility are based on interviews with student raters of only one primary study (InDemA). However, the raters' statements were very homogeneous and consistent with project-internal feedback about the feasibility from raters in the project STI-D. Hence, it can be presumed that the key challenges in the application of the instrument were identified. In addition, the Dutch results for the identified subscales are based on a Mokken Scale analysis, which differs from a factor analysis. Thus, potential effects of the different methods might be studied.

\section{Corresponding address \\ M. Dichter}

Deutsches Zentrum für Neurodegenerative

Erkrankungen (DZNE)

Stockumer Str. 12, 58453 Witten

Germany

Martin.Dichter@dzne.de

Conflict of interest. The corresponding author states that there are no conflicts of interest.

Acknowledgment. For the providing of data, we would like to thank the two teams of the STI-D und InDemA project. We also thank the student raters for their willingness to participate in the expert interviews.

\section{References}

1. Aiken LH, Buchan J, Sochalski J et al (2004) Trends in international nurse migration. Health Aff (Millwood) 23:69-77

2. Bartholomeyczik S, Hardenacke D, Bureick G et al (2010) Interdisziplinäre Implementierung von Qualitätsinstrumenten zur Versorgung von Menschen mit Demenz in Altenheimen (InDemA). Z Gerontol Geriatr 43:71

3. Bouman IEA, Ettema TP, Wetzels RB et al (2010) Evaluation of Qualidem: a dementia-specific quality of life instrument for persons with dementia in residential settings; scalability and reliability of subscales in four Dutch field surveys. Int J Geriatr Psychiatry 26:711-722
4. Brod M, Stewart AL, Sands L et al (1999) Conceptualization and measurement of quality of life in dementia: the dementia quality of life instrument (DQoL). Gerontologist 39:25-35

5. Dichter M, Halek M, Bartholomeyczik S (2009) Measuring psycho-social aspects of people suffering from dementia in nursing homes with Quality of Life (QoL) Instruments. In: Alzheimer Europe Conference - Brussels. Brussels, Belgium

6. Ettema TP (2007) The development of a dementia specific Quality of Life scale: the first phase of construction. In: Ettema PT (ed) The construction of a dementia-specific Quality of Life instrument rated by professional caregivers: The QUALIDEM. Vrije Universiteit Amsterdam, Amsterdam, p 51-62

7. Ettema TP, Dröes R-M, De Lange J et al (2007) QUALIDEM: Development and evaluation of a dementia specific Quality of Life instrument. Scalability, reliability and internal structure. Int J Geriatr Psychiatry 22:549-556

8. Ettema TP, Dröes R-M, De Lange J et al (2005) A review of quality of life instruments used in dementia. Qual Life Res 14:675-686

9. Ettema TP, Dröes R-M, De Lange J et al (2005) The concept of quality of life in dementia in the different stages of the disease. Int Psychogeriatr 17:353-370

10. Ferri CP, Prince $M$, Brayne $C$ et al (2005) Global prevalence of dementia: a Delphi consensus study. Lancet 366:2112-2117

11. Field A (2009) Discovering Statistics using SPSS. SAGE Publications Ltd, London

12. Folstein MF, Folstein SE, Mchugh PR (1975) Minimental state. A practical method for grading the cognitive state of patients for the clinician. J Psychiatr Res 12:189-198

13. Harris P, Sterin G (1999) Insider's perspective: defining and preserving the self of dementia. J Ment Health Aging 5:241-256

14. Kaiser HF (1974) An index of factorial simplicity. Psychometrika 39:31-36

15. Kane RA, Kling KC, Bershadsky B et al (2003) Quality of life measures for nursing home residents. J Gerontol Med Sci 58:M240-M248

16. Moyle W, Mcallister M, Venturato L et al (2008) Quality of life and dementia. Dementia 6:175-191

17. Nordheim J, Liebich M (2010) Demenz und Herausforderndes Verhalten: Ergebnisse einer Studie zum strukturierten Pflegekonzept "Serial Trial Intervention" (STI-D). Z Gerontol Geriatr 43:70-71

18. Ready RE, Ott BR (2003) Quality of Life measures for dementia. Health Qual Life Outcomes 1:1-9

19. Reisberg B, Lauter H (1993) Clinical dementias staging methodologies. The International Psychogeriatric Association Newsletter 10:16-17

20. Smith SC, Lamping DL, Banerjee S et al (2005) Measurement of health-related quality of life for people with dementia: development of a new instrument (DEMQOL) and an evaluation of current methodology. Health Technol Assess NHS R\&D HTA Programme 9:1-110 